\title{
Plasma irisin is elevated in type 2 diabetes and is associated with increased E-selectin levels
}

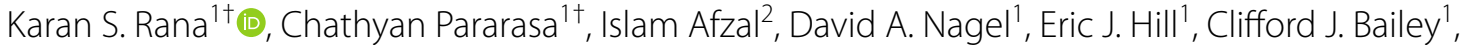 \\ Helen R. Griffiths ${ }^{6}$, loannis Kyrou ${ }^{2,3,4}$, Harpal S. Randeva ${ }^{2,3,4}$, Srikanth Bellary ${ }^{1,5}$ and James E. Brown ${ }^{1,2^{*}}$
}

\begin{abstract}
Background: Irisin is a hormone released mainly from skeletal muscle after exercise which increases adipose tissue energy expenditure. Adipocytes can also release irisin after exercise, acting as a local adipokine to induce white adipose tissue to take on a brown adipose tissue-like phenotype, suggesting that irisin and its receptor may represent a novel molecular target for the treatment of obesity and obesity-related diabetes. Previous reports provide conflicting evidence regarding circulating irisin levels in patients with type 2 diabetes (T2DM).
\end{abstract}

Methods: This study investigated plasma irisin concentrations in 79 T2DM individuals, assessing potential associations with measures of segmental body composition, markers of endothelial dysfunction and peripheral blood mononuclear cell telomere length (TL).

Results: Resting, overnight-fasted plasma irisin levels were significantly higher in this group of T2DM patients compared with levels we previously reported in healthy volunteers $(p<0.001)$. Moreover, plasma irisin displayed a positive correlation with body mass index $(p=0.04)$, body fat percentage $(p=0.03), \operatorname{HbA1c}(p=0.03)$ and soluble E-selectin $(p<0.001)$. A significant negative association was observed between plasma irisin and visceral adiposity $(p=0.006)$ in T2DM patients. Multiple regression analysis revealed that circulating soluble E-selectin levels could be predicted by plasma irisin $(p=0.004$ ). Additionally, cultured human umbilical vein endothelial cells (HUVEC) exposed to $200 \mathrm{ng} /$ $\mathrm{ml}$ irisin for $4 \mathrm{~h}$ showed a significant fourfold increase in E-selectin and 2.5-fold increase in ICAM-1 gene expression $(p=0.001$ and $p=0.015$ respectively), and there was a 1.8-fold increase in soluble E-selectin in conditioned media $(\mathrm{p}<0.05)$.

Conclusion: These data suggest that elevated plasma irisin in T2DM is associated with indices of adiposity, and that irisin may be involved in pro-atherogenic endothelial disturbances that accompany obesity and T2DM. Accordingly, irisin may constitute a potentially novel therapeutic opportunity in the field of obesity and cardiovascular diabetology.

Keywords: Irisin, Type 2 diabetes, Soluble E-selectin, Endothelial

\section{Introduction}

Irisin is a recently identified hormone derived from the fibronectin type III domain-containing (FNDC5) gene that is released mainly from skeletal muscle after exercise

\footnotetext{
${ }^{*}$ Correspondence: j.e.p.brown@aston.ac.uk

${ }^{\dagger}$ Dr Karan S. Rana and Dr Chathyan Pararasa contributed equally to this work

${ }^{1}$ Aston Research Centre for Healthy Ageing and School of Life and Health Sciences, Aston University, Birmingham B4 7ET, UK

Full list of author information is available at the end of the article
}

or exposure to cold [1-3]. The ability of irisin, via yet undetermined receptors, to reprogram white adipose tissue (WAT) cells to take on the phenotype of brown adipose tissue (BAT) has been proposed as a potential therapeutic target for metabolic disorders, including obesity and type 2 diabetes (T2DM) [4-7]. Indeed, exposure to irisin leads to suppressed expression of several genes characteristic to WAT, whilst there is a concomitant increase in uncoupled respiration via induction of uncoupling protein-1 (UCP1) expression and altered 
expression of other established BAT genes [8-10]. Thus irisin can promote energy expenditure via thermogenesis [11]. Release of irisin has also been described from adipose tissue, suggesting that this hormone is an adipokine, as well as a myokine $[12,13]$. Irisin release from WAT, as from muscle, is stimulated by exercise and reduced in fasted animals [12]. To date, there is conflicting evidence regarding possible association(s) between circulating irisin and body mass index (BMI): some data indicate a positive correlation [14], whilst other studies have found either no association [15] or a negative association [16]. Moreover, the role of irisin in T2DM remains unclear. Initial studies reported decreased circulating irisin levels in T2DM patients compared to healthy individuals $[17,18]$, whereas studies performed in obese individuals (some of whom had T2DM) have reported elevated levels $[14,19]$. Recent data indicate that irisin may be involved in cardiovascular physiology, with evidence emerging that it plays a role in atherosclerosis [20-22] and can predict cardiovascular disease (CVD) risk [23, 24] This highlights the potential significance of irisin as a biomarker in T2DM patients who are at an increased CVD risk [25]. Moreover, we previously reported that plasma irisin levels can predict TL, a marker of biological ageing in healthy non-obese individuals, suggesting that irisin may provide a marker of ageing, as well as energy balance [26]. Since irisin is emerging as a new factor implicated in the pathophysiology of obesity and a potential opportunity to treat obesity, further appreciation of the role of irisin in obesity-related diabetes is required, particularly in relation to factors implicated in endothelial dysfunction and atherosclerosis, such as E-selectin.

E-selectin is a key adhesion molecule which alongside other endothelial adhesion molecules, serves to anchor leukocytes to the endothelium in inflammation and elevated soluble E-selectin levels have been identified in hypertension, diabetes and hyperlipidemia [27]. E-selectin is not constitutively expressed by endothelial cells [28], but is known to be expressed and released from activated endothelium both in vitro [29] and in vivo [30]. E-selectin expression is stimulated by exposure to inflammatory molecules including tumour necrosis factoralpha (TNF- $\alpha$ ) and interleukin-1 (IL-1) [31].

The present study investigated plasma irisin levels in a cohort of T2DM patients, examining associations between plasma irisin, indices of adiposity, ageing and circulating markers of endothelial dysfunction. The effects of exposure of primary cultured human endothelial cells to high irisin levels on expression and secretion of soluble forms of adhesion molecules was also investigated.

\section{Materials and methods}

\section{Study participants}

A group of 79 individuals with T2DM (42 males, 37 females; mean BMI $31.5 \pm 5.4 \mathrm{~kg} / \mathrm{m}^{2}$ ) was recruited from the diabetes outpatient clinics at the Heart of England NHS Foundation Trust, Birmingham, UK. The study exclusion criteria included pregnancy, recent hospitalization, other significant disease (e.g. cancer or immune disorders), and other significant treatments (e.g. oral corticosteroids). All subjects were asked to fast overnight for a minimum of $8 \mathrm{~h}$ and to refrain from exercise for at least $12 \mathrm{~h}$ prior to study sampling. The study was approved by the Aston University Research Ethics Committee and the Staffordshire NHS Research Ethics Committee and written informed consent was given by all participants according to the principles of the Declaration of Helsinki.

\section{Anthropometric and biochemical measures}

Segmental body composition was measured using bioelectrical impedance analysis (BIA) (BC-601 Bioimpedance Analyser Tanita $\left.{ }^{\circledR}\right)$. Analyses included segmental fat mass (FM), fat free mass (FFM) and a calculated visceral fat score (calculated by the manufacturer's software; a score of 1-12 is considered healthy; $13-59$ indicates excess visceral fat) in all subjects. Abdominal fat and fat free muscle readings are subtracted from other segmental readings to estimate the body trunk. Body weight was measured to the nearest $0.1 \mathrm{~kg}$ and height to the nearest $1 \mathrm{~cm}$, whilst BMI was determined as body weight in kilograms divided by the square of the height in metres $\left(\mathrm{kg} / \mathrm{m}^{2}\right)$. A fasting sample of venous whole blood was collected into $\mathrm{K}^{+}$-EDTA coated tubes (Vacutainer, Becton-Dickinson, UK). Plasma was separated by cooled centrifugation ( $1300 \mathrm{~g}$ for $10 \mathrm{~min}$ ) and samples were stored at $-80{ }^{\circ} \mathrm{C}$ until analysed. For telomere length analysis, genomic DNA extraction was performed on whole blood aliquots using the QIAamp ${ }^{\circledR}$ DNA blood mini kit (Qiagen, UK). DNA was resuspended in elution buffer (10 mM Tris. Cl; $0.5 \mathrm{mM}$ EDTA; pH 9.0). Isolated DNA was quantified using the NanoDrop-1000 (NanoDrop Technologies, USA) and diluted in pure water to a concentration of $5 \mathrm{ng} / \mu \mathrm{l}$ and stored at $-80^{\circ} \mathrm{C}$.

Fasting whole blood glucose was measured using an Accucheck Advantage blood glucose meter. Glycated haemoglobin (HbA1c) was measured by mass spectrometry. Plasma irisin (Phoenix Peptides, Germany), leptin, soluble E-selectin, soluble thrombomodulin, C-reactive protein (CRP) (R\&D Systems, UK) and insulin (Mercodia, Sweden) concentrations were all assessed by ELISA following protocols provided by the manufacturers. The 
homeostatic model assessment (HOMA) method was used to assess $\beta$-cell function (HOMA- $\beta$ ), and insulin resistance (HOMA-IR) was used to derive insulin sensitivity (HOMA-S) as previously described [32], according to the following equations:

$$
\begin{aligned}
\text { HOMA- } \beta \%= & {[20 \times \text { fasting insulin }(\mathrm{mIU} / \mathrm{l})] / } \\
& \text { Glucose }(\mathrm{mmol} / \mathrm{l})-3.5 \\
\text { HOMA-IR }= & {[\text { Glucose }(\mathrm{mmol} / \mathrm{l})} \\
& \times \text { fasting insulin }(\mathrm{mIU} / \mathrm{l})] / 22.5 \\
\text { HOMA-S }= & 1 / \text { HOMA-IR }
\end{aligned}
$$

Relative telomere length analysis was measured using an established real-time polymerase chain reaction (RT$\mathrm{PCR}$ ) to produce a relative expression ratio of telomeric DNA to genomic DNA control (T/S ratio) $[26,33]$.

\section{Cell culture and gene expression analysis}

Early passage primary human umbilical vein endothelial cells (HUVECs) (Caltag Medsystems, UK) were grown in supplemented proprietary human large vessel endothelial cell basal medium (Caltag Medsystems, UK) in a $37{ }^{\circ} \mathrm{C}, 5 \% \mathrm{CO}_{2}$ humidified incubator. Cells were seeded at $1 \times 10^{5}$ cells per well in a 12-well plate and allowed to attach for $48 \mathrm{~h}$ before exposure to 0,20 and $200 \mathrm{ng} / \mathrm{ml}$ recombinant human irisin (Caymen Chemicals, USA) for 4 or $24 \mathrm{~h}$. Total RNA was isolated using EZNA RNA Isolation kit (VWR, UK), and treated with DNase (Promega, UK) to remove any traces of genomic material. RNA quantification was performed using the Nanodrop 1000 (Thermofisher). Samples (500 ng) of total RNA were reverse transcribed using Precision nanoscript ${ }^{\mathrm{TM}}$ reverse transcriptase (Primerdesign, Southampton UK) and oligo ${ }_{d} \mathrm{~T}$ primers (PrimerDesign, Southampton, UK). cDNAs were amplified using a Stratagene MX3000P thermal cycler in a standard 40 -cycle $\mathrm{SYBR}^{\circledR}$ green real-time PCR reaction followed by a melt curve analysis to assess amplicon specificity. Gene expression was assessed with the following primers, E-selectin (sense AGAGGTTCCTTCCTGCCAAG, antisense CAGAGCCATTGAGGGTCCAT), P-selectin (sense CGCCTGCCTCCAGACCATCTTC, antisense CTATTCACATTCCAGAAACTCACCACAGC), ICAM1 (sense GACTCCAATGTGCCAGGCTT, antisense TAGGTGCCCTCAAGATCTCG) and PECAM1 (sense ATTGCAGTGGTTATCATCGGAGTG, antisense CTCGTTGTTGGAGTTCAGAAGTGG) were assessed. Data were normalised to expression of the housekeeping genes actin and YWHAZ (pre-validated primers purchased from Primerdesign, UK) and analysed for fold changes in gene expression using the comparative CT method with statistical analysis determined using the freely available Relative Expression Software Tool (REST 2009, http://www.qiagen.com).

\section{HUVEC ELISA for soluble E-selectin}

The concentration of soluble E-selectin in cell supernatants derived from HUVEC cells treated with 20 and $200 \mathrm{ng} / \mathrm{ml}$ irisin for a period of 4 and $24 \mathrm{~h}$ was quantified using soluble E-selectin ELISA (R\&D Systems, UK) as per manufacturer's instructions.

\section{Statistical analysis}

Results are presented as mean \pm standard deviation (SD), unless otherwise stated. Comparisons between cohorts and analysis of E-selectin expression data were performed using unpaired $t$ tests. For analysis within the cohort of T2DM individuals, associations between plasma irisin and other circulating factors with anthropometric measures were explored individually using Pearson's bivariate correlations. Natural log-transformed telomere length was assessed to ensure that associations with $\mathrm{T} / \mathrm{S}$ ratio always remained non-negative, ensuring that the decline in telomere length with age followed a biologically consistent negative exponential decay model. Subsequently, linear regression was used to investigate whether plasma irisin levels were significantly predictive of plasma soluble E-selectin levels. For all analyses a $p$ value of $<0.05$ was considered to be statistically significant.

\section{Results}

Body anthropometry and biochemical analyses of T2DM patients

Table 1 presents the results of the anthropometric and biochemical analyses in the T2DM study cohort. Overall, the T2DM patients exhibited measurements indicative of central obesity, including an average BMI $>30 \mathrm{~kg} /$ $\mathrm{m}^{2}$ with high average body fat and abdominal (trunk) fat percentages (34.9 and $34.1 \%$, respectively) and an average visceral fat score above the healthy range ( $>13$ ). Biochemical analyses showed an expected elevation of fasting blood glucose $(9.9 \mathrm{mmol} / \mathrm{l})$, with concomitantly elevated levels of pro-inflammatory factors, including leptin $(1530 \mathrm{ng} / \mathrm{ml})$, C-reactive protein $(4.5 \mu \mathrm{g} / \mathrm{ml})$ and soluble E-selectin $(50.9 \mathrm{ng} / \mathrm{ml})$. In the T2DM cohort overnight-fasted, resting, plasma irisin levels were significantly higher than levels previously noted in healthy volunteers $(175.4 \pm 131 \mathrm{ng} / \mathrm{ml}$ vs. $46.7 \pm 32.4 \mathrm{ng} / \mathrm{ml}$; $\mathrm{p}<0.0001)$.

\section{Associations of plasma irisin with biochemical and anthropometric factors in type 2 diabetes}

Pearson's bivariate correlations between plasma irisin and anthropometric and biochemical measures and T/S 
Table 1 Anthropometric and biochemical measurements in individuals with type 2 diabetes (T2DM)

\begin{tabular}{ll}
\hline Anthropometric and biochemical analysis & Type 2 diabetes cohort \\
\hline Cohort size & 79 \\
Men & 42 \\
Women & 37 \\
Age (years) & $56 \pm 12$ \\
Height (cm) & $165 \pm 10$ \\
Weight (kg) & $87 \pm 20.5$ \\
Body mass index (kg/m²) & $31.5 \pm 5.4$ \\
Total fat (\%) & $34.9 \pm 9.3$ \\
Total muscle (kg) & $53 \pm 11.8$ \\
Abdominal (trunk) fat (\%) & $34.1 \pm 9.4$ \\
Abdominal (trunk) muscle (kg) & $29 \pm 5.7$ \\
Visceral fat score (0-60) & $13.2 \pm 5.5$ \\
Fasting blood glucose (mmol/l) & $9.9 \pm 3.8$ \\
HbA1c (mmol/mol) & $70.5 \pm 17.6$ \\
Fasting insulin (mU/l) & $29.1 \pm 42.6$ \\
HOMA $\beta(\%)$ & $67.2 \pm 67.9$ \\
HOMA-S & $74 \pm 71$ \\
Telomere length (T/S ratio) & $1.6 \pm 0.2$ \\
Irisin (ng/ml) & $175.4 \pm 131$ \\
Leptin (pg/ml) & $1529 \pm 1372$ \\
Thrombomodulin (ng/ml) & $6.6 \pm 6.3$ \\
E-selectin (ng/ml) & $50.9 \pm 21.4$ \\
C-reactive protein ( $\mu \mathrm{g} / \mathrm{ml})$ & $4.5 \pm 3.99$ \\
\hline Homestaic &
\end{tabular}

Homeostatic model assessment for beta cell function (HOMA- $\beta$ ) and insulin sensitivity (HOMA-S). Data are presented as mean \pm S.D. for normal continuous variables

ratio were assessed and associations are represented in Table 2. BMI $(\mathrm{p}=0.04)$, total fat percentage $(\mathrm{p}=0.033)$, HbA1c $(\mathrm{p}=0.032)$ and E-selectin $(\mathrm{p}<0.0001)$ exhibited significant positive associations with plasma irisin levels in the T2DM cohort. Visceral fat score $(\mathrm{p}=0.006)$ displayed a significant negative association with plasma irisin levels, as did age $(\mathrm{p}=0.001)$ and circulating leptin $(\mathrm{p}=0.02)$. No other factors measured in this study displayed any significant associations with plasma irisin in T2DM subjects, including T/S ratio which, as previously shown, is predicted by plasma irisin in healthy individuals [33]. Figure 1 shows the scatterplots of these associations.

\section{Plasma irisin predicts E-selectin levels in type 2 diabetes}

Multivariate regression analysis was used to test the most significant associations with soluble E-selectin. In the T2DM cohort, plasma irisin was significantly predictive for soluble E-selectin, with a $\beta$ value of 0.382 and an $r^{2}$ value of $24.7(\mathrm{p}=0.004)$.
Table 2 Results of Pearson's bivariate correlations analysis

\begin{tabular}{lcc}
\hline Measurement & $\boldsymbol{\beta}$ value & p value \\
\hline Age & -0.364 & 0.001 \\
Height & -0.171 & 0.13 \\
Weight & 0.089 & 0.43 \\
Body mass index (kg/m²) & 0.223 & 0.04 \\
Total fat (\%) & 0.241 & 0.03 \\
Total muscle (kg) & -0.134 & 0.23 \\
Abdominal (trunk) fat (\%) & 0.062 & 0.59 \\
Abdominal (trunk) muscle (kg) & -0.173 & 0.13 \\
Visceral fat score & -0.3 & 0.006 \\
Fasting blood glucose (mmol/l) & -0.03 & 0.79 \\
HbA1c (mmol/mol) & 0.28 & 0.03 \\
Fasting insulin (mU/l) & 0.08 & 0.46 \\
HOMA $\beta(\%)$ & 0.01 & 0.92 \\
HOMA-S & 0.05 & 0.65 \\
Leptin (pg/ml) & -0.24 & 0.02 \\
Thrombomodulin (ng/ml) & -0.16 & 0.15 \\
E-selectin (ng/ml) & 0.43 & $<0.0001$ \\
C-reactive protein $(\mu \mathrm{gg} / \mathrm{ml})$ & 0.05 & 0.62 \\
T/S ratio & -0.11 & 0.3 \\
\hline Pearson's bivaiac & &
\end{tabular}

Pearson's bivariate correlations between anthropometric/biochemical parameters and fasting plasma irisin levels. Homeostatic model assessment for beta cell function (HOMA $\beta$ ) and insulin sensitivity (HOMA-S). Data are represented as positive or negative correlation coefficients with $p$ values $<0.05$ indicating statistical significance (in italic text)

\section{E-selectin and ICAM-1 gene expression is induced} in HUVECs by exposure to high but not low irisin levels

To investigate the biological mechanism underlying the association between irisin and E-selectin, HUVEC cells were treated for 4 or $24 \mathrm{~h}$ with low $(20 \mathrm{ng} / \mathrm{ml})$ and high $(200 \mathrm{ng} / \mathrm{ml})$ recombinant human irisin. SYBR Green ${ }^{\circledR}$ Real-time PCR analysis of E-selectin and ICAM-1 gene expression showed that exposure to high irisin induced a fourfold and 2.5-fold increase in mRNA expression respectively compared to control (Fig. 2b, p < 0.05). Exposure to low irisin caused no significant difference in E-selectin expression levels (Fig. 2a, p > 0.05). No other markers of endothelial inflammation tested, i.e. P-selectin, and platelet endothelial cell adhesion molecule-1 (PECAM-1), were altered by exposure to irisin. Expression of E-selectin after $24 \mathrm{~h}$ of treatment was returned to basal levels (Fig. 2c, d).

Soluble E-selectin concentration is increased in culture supernatant obtained from HUVECs exposed to high irisin concentrations for $4 \mathrm{~h}$ and returns to baseline after $24 \mathrm{~h}$ As measured by ELISA, culture supernatants from HUVECs treated for $4 \mathrm{~h}$ with $200 \mathrm{ng} / \mathrm{ml}$ recombinant 

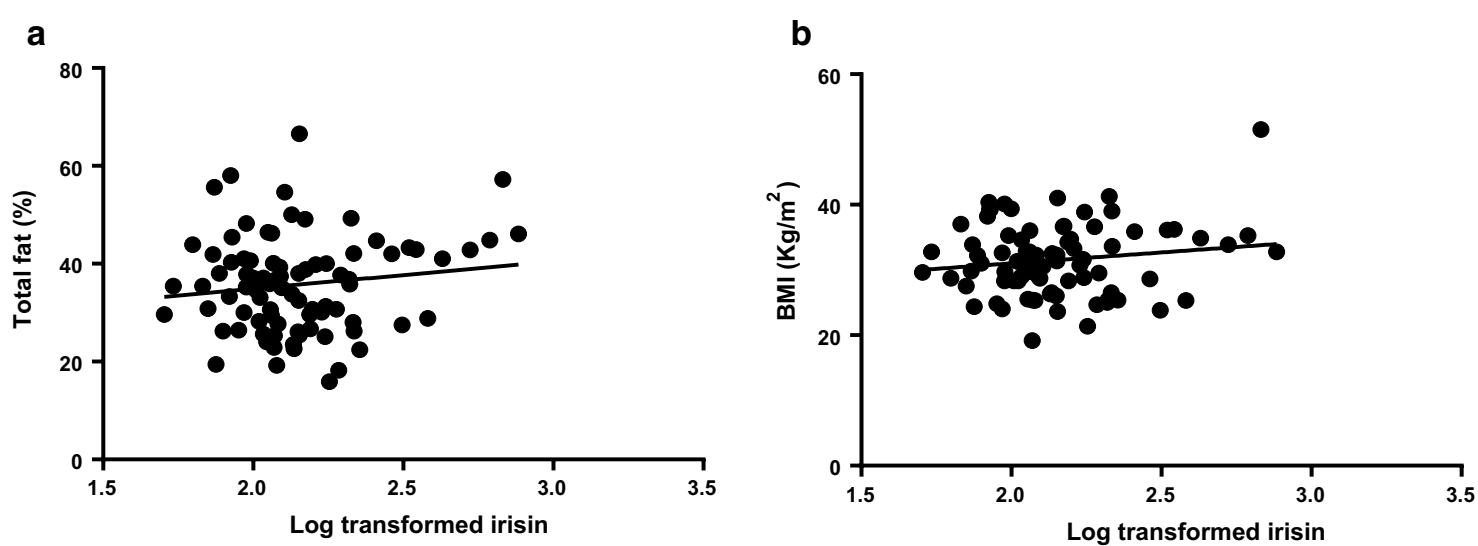

C

d
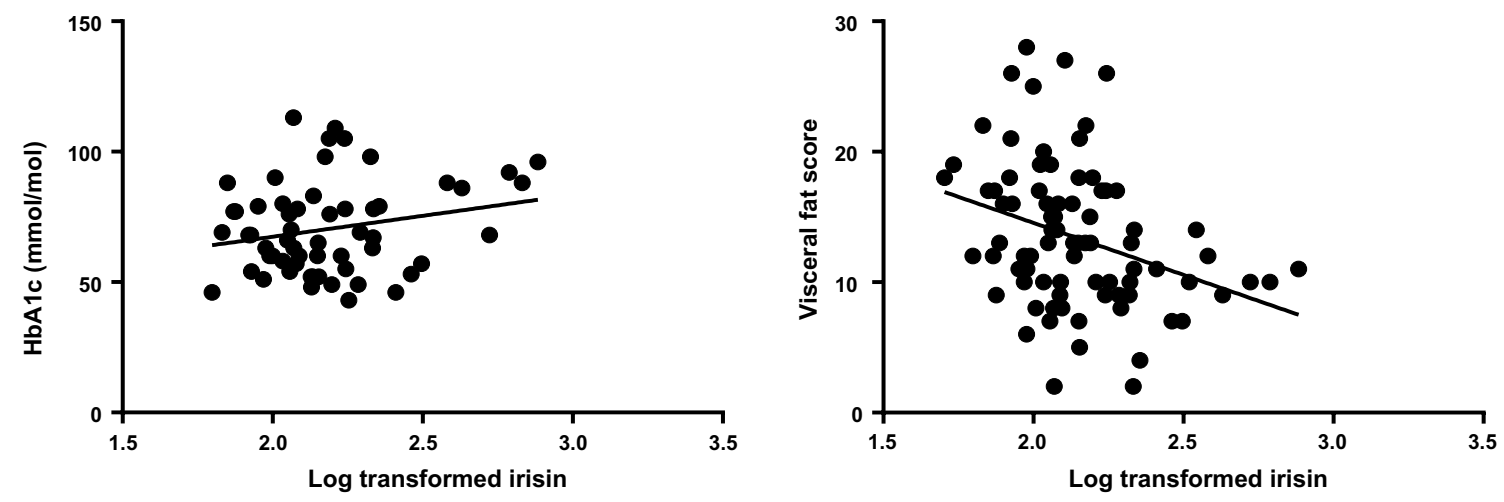

e

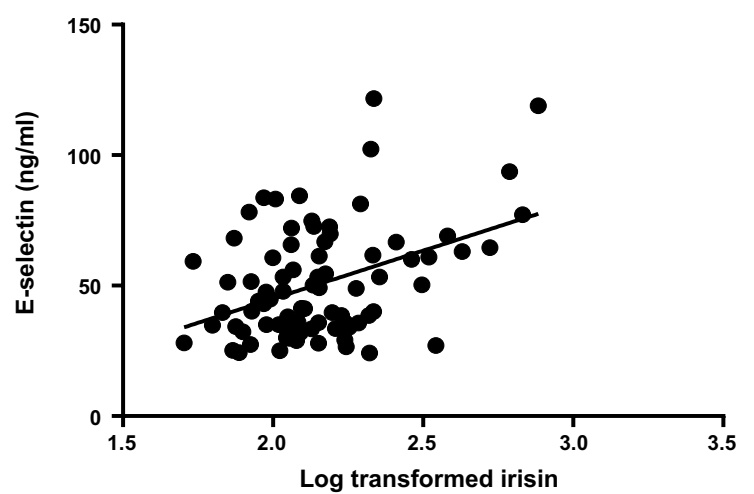

Fig. 1 Associations between plasma irisin levels and anthropometric/biochemical measures. In our study cohort of type 2 diabetic patients, Pearson's correlation tests showed significant positive associations between plasma irisin and body mass index (BMI) (a $p=0.04)$; total fat (\%) (b $p=0.03) ; \mathrm{HbA1c}(\mathbf{c} p=0.032)$ and E-selectin $(\mathbf{e} p<0.001)$; and a significant negative association between plasma irisin levels and the visceral fat score $(\mathbf{d} p=0.006)$

human irisin had 1.8-fold increased soluble E-selectin concentration compared to HUVECs treated with $20 \mathrm{ng} / \mathrm{ml}$ of irisin for $4 \mathrm{~h}$ (Fig. 3, p < 0.05). Incubation for $24 \mathrm{~h}$ with $200 \mathrm{ng} / \mathrm{ml}$ irisin resulted in soluble E-selectin concentrations similar to the levels detected in the control group treated with regular growth media. HUVECs treated with TNF- $\alpha$ produced the highest levels of soluble E-selectin (Fig. 3, p $\leq$ 0.0001) and were used as a positive control. 

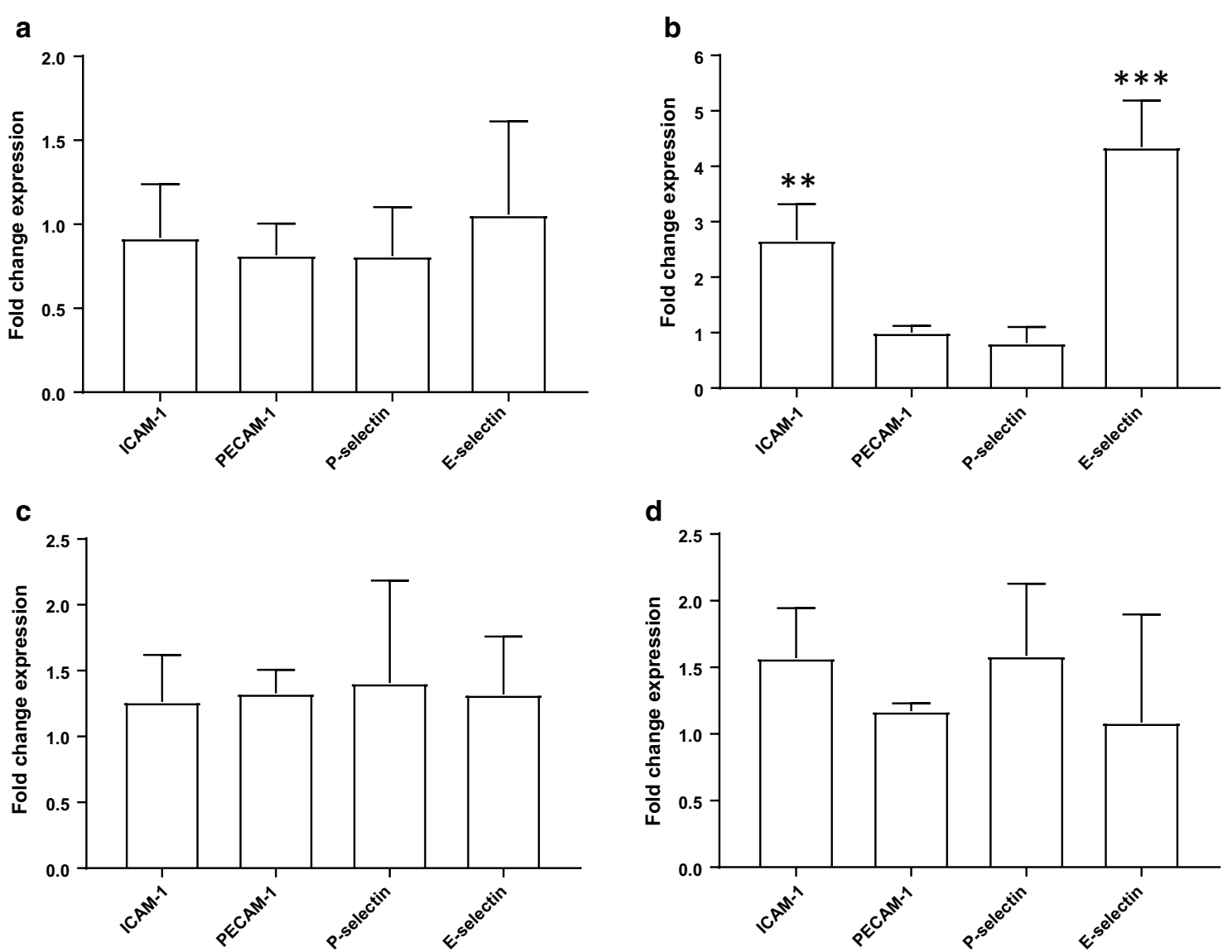

Fig. 2 Exposure to recombinant human irisin induces E-selectin and ICAM-1 gene expression in primary HUVECs. Real-time PCR analysis of irisin-treated HUVEC, displaying intracellular adhesion molecule 1 (ICAM1), platelet endothelial cell adhesion molecule (PECAM1), P-selectin and E-selectin mRNA expression levels. a Exposure to $20 \mathrm{ng} / \mathrm{ml}$ irisin for $4 \mathrm{~h}$ caused no changes in gene expression relative to control. $\mathbf{b}$ Exposure to $200 \mathrm{ng} / \mathrm{ml}$ irisin for $4 \mathrm{~h}$ induced a fourfold increase in E-selectin and 2.5-fold increase in ICAM-1 mRNA expression compared to control ( $p=0.001$ and $p=0.014$ respectively). c Exposure to $20 \mathrm{ng} / \mathrm{ml}$ irisin for $24 \mathrm{~h}$ caused no significant alteration in expression of genes associated with endothelial dysfunction relative to control and neither did, $\mathbf{d}$ exposure to $200 \mathrm{ng} / \mathrm{ml}$ for $24 \mathrm{~h}$. Values normalised to actin and YWHAZ expression $(n=4)$. ${ }^{* *} p<0.01,{ }^{* * *} p<0.001$ and ${ }^{* * *} p<0.0001$

\section{Discussion}

The current study provides evidence that circulating irisin levels are increased in fasted obese T2DM patients compared with levels which we have previously established for healthy non-diabetic controls [33]. The increased circulating irisin in T2DM showed a significant positive association with plasma soluble E-selectin. The anthropometric analyses in the present study revealed a high BMI with high total and abdominal body fat percentage within the T2DM cohort, whereas the muscle mass of these patients did not differ significantly from values previously reported for a non-diabetic cohort [33]. As irisin is a myokine, this raises the possibility that the increased irisin levels in the T2DM patients may be entering the circulation from a tissue source other than muscle. The strong association between plasma irisin and measures of obesity (including percentage truncal fat), suggest that circulating irisin in this study cohort may be determined by the degree of adiposity. The present results are consistent with previously published data showing correlations between body fat and circulating irisin levels [14, 23, 34].

Although the elevation of circulating irisin in obese T2DM may constitute a compensatory response to decreased energy expenditure, possibly due to lack of exercise or innate defects in metabolism $[20,23]$ it is also plausible that excess adipose tissue in these patients could provide an extra source of irisin. This is consistent with recent studies in obese subjects showing that plasma irisin decreased markedly in response to a hypocaloric diet and weight loss, together with significant reductions in hyperglycaemia and hyperinsulinaemia [35-37].

It should be also noted that the measurement of irisin in biological samples via immunological methodologies 

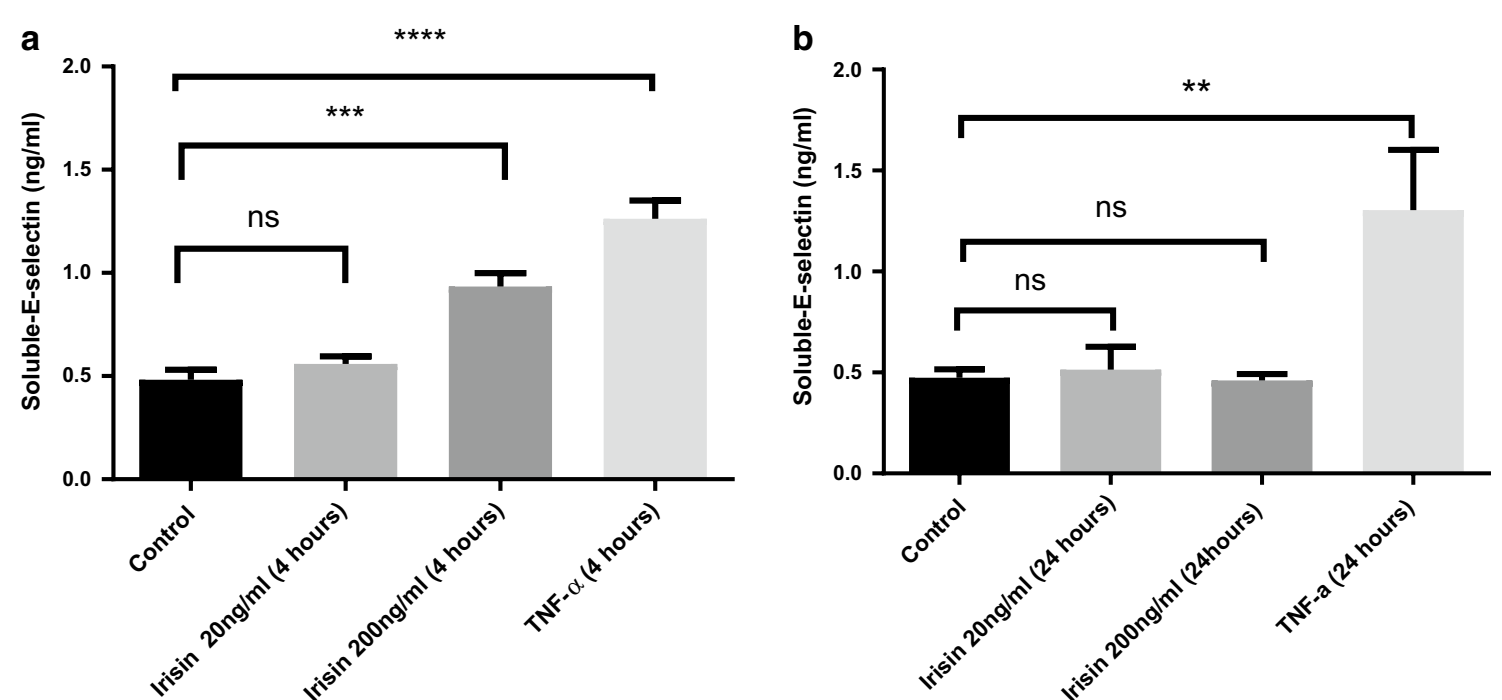

Fig. 3 The effect of recombinant human irisin on soluble E-selectin in primary HUVECs. HUVEC cells were treated for a 4 and $\mathbf{b} 24 \mathrm{~h}$ with recombinant human irisin $(20$ and $200 \mathrm{ng} / \mathrm{ml})$. TNF-a treatment $(10 \mathrm{ng} / \mathrm{ml}$ ) was used as a positive control (negative control treated only with regular growth media). Supernatant was collected and soluble E-selectin was measured by ELISA. Data was analysed using one way ANOVA with Tukeys multiple comparison test. Data are presented as mean \pm SEM; statistical significance was set at $p<0.05 .{ }^{* *} p<0.01,{ }^{* * *} p<0.001$ and ${ }^{* * * *} p<0.0001$

is not without controversy. Indeed, there is some disparity in the reported levels of irisin in serum or plasma depending on the methodology used in detecting it [38]. As such, there is currently no universally accepted 'reference range' or normal value for circulating irisin in healthy individuals and some even question its existence [39]. Although it has been suggested that a 'normal' circulating concentration of irisin may fall in the narrow range of 3.6-4.6 ng/ml [40], plasma irisin levels similar to those observed in the present study have been independently reported previously [41, 42]. Moreover, the ELISA used in the present study has been previously tested against both Western blotting [43] and mass spectrometry [44].

\section{Irisin and T2DM}

The presently observed plasma irisin concentrations in obese T2DM are interestingly not consistent with previous studies showing lower levels of circulating irisin in T2DM compared to healthy subjects. However, the newly diagnosed T2DM patients in the previous study by Choi et al. were younger, and with a markedly lower BMI compared to the present subjects [45]. Thus, the differences in circulating irisin levels between the studies may be at least partly related to these phenotypic variables. Furthermore, whilst the cohort characteristics in the study by Liu et al. were closer to the present cohort, the higher mean BMI herein may account for the differences in irisin values [46]. The absence of muscle mass and body fat measures in these previous studies makes it difficult to assess the extent of adiposity in their subjects. Additionally, it is possible that differences of ethnicity, diet and parameters identified in the present study may have influenced the irisin levels. The importance of a link between adiposity and circulating irisin cannot be overlooked, particularly if obese individuals are exposed to chronically elevated plasma irisin levels which could potentially confer a state of 'irisin resistance'. Youn et al, examined serum irisin levels in a cohort of 424 subjects, classifying them according to lower, middle and upper tertiles of skeletal muscle to visceral fat ratio (SVR). Serum irisin was correlated with favourable metabolic phenotypes in those subjects within the upper tertile. However, there were no such correlations in the lower tertile. The authors concluded that circulating irisin is dysfunctionally altered in subjects with lower skeletal muscle mass and higher visceral fat [47] which carries implications for any application of irisin as a potential anti-obesity treatment $[5,12]$.

Moreover, in the present study a strong positive correlation was noted between $\mathrm{HbA1c}$ and plasma irisin levels, suggesting a relationship between circulating irisin levels and glycaemic control. This is supported by previous research that indicated that plasma irisin is associated with elevated blood glucose concentrations [48], whilst evidence also exists that irisin can increase glucose uptake in skeletal muscle cells in vitro in an AMPK-dependent manner [49]. Further work is required therefore to clarify the potential role of irisin in glucose homeostasis and metabolic disease. 


\section{Irisin and soluble E-selectin}

In addition to the associations between anthropometric measures and plasma irisin levels, there was a strong positive association between irisin and soluble E-selectin levels. Multiple regression analysis showed that amongst the factors that exhibited a significant association with soluble E-selectin levels (Table 2), soluble E-selectin was the only factor to significantly predict plasma irisin levels. This is an important finding since elevated soluble E-selectin levels are a key marker of endothelial dysfunction in T2DM [50,51], which accompanies diabetes-related micro- and macro-vascular complications [52-54]. To further explore this hypothesis, we utilized HUVEC cells as a model of the endothelium and observed that exposure to irisin, at concentrations comparable to those in many of the obese T2DM patients of this study, induced a significant increase in E-selectin gene and protein expression (Figs. 2, 3). Since the concentration of soluble E-selectin is directly proportional to its cell surface expression [55], this supports a potential role for irisin in increasing cell surface expression of E-selectin. The precise physiological role of soluble E-selectin is yet to be fully elucidated, although studies have shown that E-selectin can exert a chemotactic signal towards neutrophils, and may trigger $\mathrm{T}$ cell migration. Existing literature has reported a positive relationship between soluble E-selectin and pro-inflammatory chemokines, oxidative stress, endothelial dysfunction and incidences of T2DM and CVD [56, 57]. Additionally, Tabak et al. have previously reported a relationship between irisin and low-grade inflammation, a hallmark of metabolic syndrome [58]. Therefore, circulating soluble E-selectin levels are useful as a clinical tool to support a diagnosis of acute inflammatory processes and atherogenic risk [59]. The mechanism(s) of action of irisin in endothelial cell activation remains to be clarified, however the evidence presented here suggests that irisin may provide a novel link between increased adiposity and endothelial dysfunction.

\section{Conclusion}

The benefits of exercise in obesity and diabetes are well known and the prospect of utilising newly discovered hormonal pathways that may mimic these effects is tantalising [60]. The discovery of irisin and its potential role in energy regulation provide a potential step in this direction. Since the initial discovery of irisin by Bostrom et al. there have been several clinical studies investigating associations between circulating irisin and body composition and T2DM [61]. The results so far have been inconsistent, with the exact role of irisin in metabolic disorders yet to be fully elucidated possibly relating to differences in study methodology, which either focus on either skeletal muscle or adipose tissue. The current study considers both tissue types, however the precise mechanisms by which irisin is regulated and released from both muscle and adipose tissue, and also the diverse effects of circulating irisin which impact nutrient homeostasis and endothelial function are yet to be elucidated.

\begin{abstract}
Abbreviations
BMI: body mass index; BAT: brown adipose tissue; CVD: cardiovascular disease; CRP: C-reactive protein; FFM: fat free mass; FNDC5: fibronectin type III domaincontaining; HUVECs: human umbilical vein endothelial cells; IL-1: interleukin-1; ICAM1: intracellular adhesion molecule 1; PECAM-1: platelet endothelial cell adhesion molecule-1; RT-PCR: real-time polymerase chain reaction; FM: segmental fat mass; SVR: skeletal muscle to visceral fat ratio; TL: telomere length; HOMA: the homeostatic model assessment; TNF-a: tumour necrosis factor-alpha; T2DM: type 2 diabetes; UCP1: uncoupling protein-1; WAT: white adipose tissue.
\end{abstract}

\section{Authors' contributions}

KSR, JEB made substantial contributions to the study conception, design and acquisition and analysis of data, and was involved in drafting and revising the manuscript. CP made substantial contributions to acquisition of data, or analysis and interpretation of data and was involved in drafting and revising the manuscript. IA made substantial contributions to the analysis and interpretation of data and was involved in drafting and revising the manuscript. DN, CJB, HRG made substantial contributions to the study conception and design and was involved in drafting and revising the manuscript. EJH, SB made substantial contributions to the study conception and design and acquisition of data and was involved in drafting and revising the manuscript. IK, HSR made substantial contributions to the interpretation of data and was involved in drafting and revising the manuscript. All authors read and approved the final manuscript.

\section{Author details \\ ${ }^{1}$ Aston Research Centre for Healthy Ageing and School of Life and Health Sciences, Aston University, Birmingham B4 7ET, UK. ${ }^{2}$ Aston Medical Research Institute, Aston Medical School, Aston University, Birmingham B4 7ET, UK. \\ ${ }^{3}$ Warwickshire Institute for the Study of Diabetes, Endocrinology and Metabo- lism (WISDEM), University Hospitals Coventry and Warwickshire NHS Trust, Coventry CV2 2DX, UK. ${ }^{4}$ Translational \& Experimental Medicine, Division of Biomedical Sciences, Warwick Medical School, University of Warwick, Coventry CV4 7AL, UK. ${ }^{5}$ Department of Diabetes and Endocrinology, Diabetes Outpatient Clinics at the Heart of England NHS Foundation Trust, Birming- ham B9 5SS, UK. ${ }^{6}$ Faculty of Health and Medical Sciences, University of Surrey, Guildford GU2 7XH, UK.}

\section{Acknowledgements}

The authors would like to acknowledge the support or research nurses at Heart of England NHS Foundation Trust and Professor Alan Nevill for guidance on statistical analysis.

Competing interests

The authors declare that they have no competing interests.

\section{Availability of data and materials}

The datasets generated and/or analysed during the current study are not publicly available but anonymised data may be available from the corresponding author on reasonable request.

\section{Consent for publication}

Not applicable.

\section{Ethics approval and consent to participate}

The study was approved by the Aston University Research Ethics Committee (Reference Project 444) and the Staffordshire NHS Research Ethics Committee (Reference 11/WM/0288) and written informed consent was given by all participants according to the principles of the Declaration of Helsinki. 


\section{Funding}

The present study was cofounded by Aston University and Heart of England NHS Foundation Trust.

\section{Publisher's Note}

Springer Nature remains neutral with regard to jurisdictional claims in published maps and institutional affiliations.

Received: 19 September 2017 Accepted: 28 October 2017 Published online: 09 November 2017

\section{References}

1. Cunha A. Basic research: irisin-behind the benefits of exercise. Nat Rev Endocrinol. 2012:8:195.

2. Lee P, Linderman JD, Smith S, Brychta RJ, Wang J, Idelson C, Perron RM, Werner CD, Phan GQ, Kammula US, et al. Irisin and FGF21 are coldinduced endocrine activators of brown fat function in humans. Cell Metab. 2014;19:302-9.

3. Panati K, Suneetha Y, Narala VR. Irisin/FNDC5-an updated review. Eu Rev Med Pharmacol Sci. 2016;20:689-97.

4. Hofmann T, Elbelt U, Stengel A. Irisin as a muscle-derived hormone stimulating thermogenesis - a critical update. Peptides. 2014:54C:89-100.

5. Sanchis-Gomar F, Lippi G, Mayero S, Perez-Quilis C, Garcia-Gimenez JL. Irisin: a new potential hormonal target for the treatment of obesity and type 2 diabetes. J Diabetes. 2012;4:196.

6. Pyrzak B, Demkow U, Kucharska AM. Brown adipose tissue and browning agents: irisin and FGF21 in the development of obesity in children and adolescents. Adv Exp Med Biol. 2015;866:25-34.

7. Leung PS. The potential of irisin as a therapeutic for diabetes. Future Med Chem. 2017;9:529-32

8. Mahajan RD, Patra SK. Irisin, a novel myokine responsible for exercise induced browning of white adipose tissue. Indian J Clin Biochem. 2013;28:102-3.

9. Huh JY, Dincer F, Mesfum E, Mantzoros CS. Irisin stimulates muscle growth-related genes and regulates adipocyte differentiation and metabolism in humans. Int J Obes. 2014;38:1538-44.

10. Zhang Y, Xie C, Wang H, Foss RM, Clare M, George EV, Li S, Katz A, Cheng $H$, Ding $Y$, et al. Irisin exerts dual effects on browning and adipogenesis of human white adipocytes. Am J Physiol Endocrinol Metab. 2016;311:E530-41.

11. Castillo-Quan JI. From white to brown fat through the PGC-1alphadependent myokine irisin: implications for diabetes and obesity. Dis Model Mech. 2012:5:293-5.

12. Moreno-Navarrete JM, Ortega F, Serrano M, Guerra E, Pardo G, Tinahones F, Ricart W, Fernandez-Real JM. Irisin is expressed and produced by human muscle and adipose tissue in association with obesity and insulin resistance. J Clin Endocrinol Metab. 2013:98:E769-78.

13. Roca-Rivada A, Castelao C, Senin LL, Landrove MO, Baltar J, Crujeiras AB, Seoane LM, Casanueva FF, Pardo M. FNDC5/irisin is not only a myokine but also an adipokine. PLoS ONE. 2013;8:e60563.

14. Stengel A, Hofmann T, Goebel-Stengel M, Elbelt U, Kobelt P, Klapp BF. Circulating levels of irisin in patients with anorexia nervosa and different stages of obesity-correlation with body mass index. Peptides. 2013;39:125-30.

15. Sanchis-Gomar F, Alis R, Pareja-Galeano H, Sola E, Victor VM, Rocha M, Hernandez-Mijares A, Romagnoli M. Circulating irisin levels are not correlated with BMI, age, and other biological parameters in obese and diabetic patients. Endocrine. 2014;46:674-7.

16. Yuksel MA, Oncul M, Tuten A, Imamoglu M, Acikgoz AS, Kucur M, Madazli R. Maternal serum and fetal cord blood irisin levels in gestational diabetes mellitus. Diabetes Res Clin Pract. 2014;104:171-5.

17. Liu JJ, Liu S, Wong MD, Tan CS, Tavintharan S, Sum CF, Lim SC. Relationship between circulating irisin, renal function and body composition in type 2 diabetes. J Diabetes Complicat. 2014:28:208-13.

18. Kurdiova T, Balaz M, Vician M, Maderova D, Vlcek M, Valkovic L, Srbecky M, Imrich R, Kyselovicova O, Belan V, et al. Effects of obesity, diabetes and exercise on Fndc5 gene expression and irisin release in human skeletal muscle and adipose tissue: in vivo and in vitro studies. J Physiol. 2014;592:1091-107.
19. Rodrigues KF, Pietrani NT, Bosco AA, Ferreira CN, Gomes KB. Circulating irisin is increased in type 2 diabetes mellitus and correlates with fasting glucose levels. Apollo Med. 2016;13:152-5.

20. Sesti G, Andreozzi F, Fiorentino TV, Mannino GC, Sciacqua A, Marini MA, Perticone F. High circulating irisin levels are associated with insulin resistance and vascular atherosclerosis in a cohort of nondiabetic adult subjects. Acta Diabetol. 2014:51:705-13.

21. Zhang $Y$, Song $H$, Zhang $Y$, Wu F, Mu Q, Jiang M, Wang F, Zhang W, Li L, Shao L, et al. Irisin inhibits atherosclerosis by promoting endothelial proliferation through microRNA. J Am Heart Assoc. 2016;5:126-5.

22. Zhang Y, Mu Q, Zhou Z, Song H, Zhang Y, Wu F, Jiang M, Wang F, Zhang $W$, Li L, et al. Protective effect of irisin on atherosclerosis via suppressing oxidized low density lipoprotein induced vascular inflammation and endothelial dysfunction. PLoS ONE. 2016;11:e0158038.

23. Hee Park K, Zaichenko L, Brinkoetter M, Thakkar B, Sahin-Efe A, Joung KE, Tsoukas MA, Geladari EV, Huh JY, Dincer F, et al. Circulating irisin in relation to insulin resistance and the metabolic syndrome. J Clin Endocrinol Metab. 2013:98:4899-907.

24. Efe TH, Acar B, Ertem AG, Yayla KG, Algul E, Yayla C, Unal S, Bilgin M, Cimen T, Kirbas O, Yeter E. Serum irisin level can predict the severity of coronary artery disease in patients with stable angina. Korean Circ J. 2017;47:44-9.

25. Taylor KS, Heneghan CJ, Farmer AJ, Fuller AM, Adler Al, Aronson JK, Stevens RJ. All-cause and cardiovascular mortality in middle-aged people with type 2 diabetes compared with people without diabetes in a large U.K. primary care database. Diabetes Care. 2013;36:2366-71.

26. Cawthon RM. Telomere measurement by quantitative PCR. Nucleic Acids Res. 2002:30:e47.

27. Roldan V, Marin F, Lip GY, Blann AD. Soluble E-selectin in cardiovascular disease and its risk factors. A review of the literature. Thromb Haemost. 2003;90:1007-20

28. Jubeli E, Moine L, Vergnaud-Gauduchon J, Barratt G. E-selectin as a target for drug delivery and molecular imaging. J Control Release. 2012;158:194-206.

29. Melrose J, Tsurushita N, Liu G, Berg EL. IFN-gamma inhibits activationinduced expression of E- and P-selectin on endothelial cells. J Immunol. 1998;161:2457-64

30. Fries JW, Williams AJ, Atkins RC, Newman W, Lipscomb MF, Collins T. Expression of VCAM-1 and E-selectin in an in vivo model of endothelial activation. Am J Pathol. 1993;143:725-37.

31. Ley K. The role of selectins in inflammation and disease. Trends Mol Med. 2003;9:263-8.

32. Matthews DR, Hosker JP, Rudenski AS, Naylor BA, Treacher DF, Turner RC. Homeostasis model assessment: insulin resistance and beta-cell function from fasting plasma glucose and insulin concentrations in man. Diabetologia. 1985;28:412-9.

33. Rana KS, Arif M, Hill EJ, Aldred S, Nagel DA, Nevill A, Randeva HS, Bailey CJ, Bellary S, Brown JE. Plasma irisin levels predict telomere length in healthy adults. Age. 2014;36:995-1001.

34. Huh JY, Panagiotou G, Mougios V, Brinkoetter M, Vamvini MT, Schneider BE, Mantzoros CS. FNDC5 and irisin in humans: I. Predictors of circulating concentrations in serum and plasma and II. mRNA expression and circulating concentrations in response to weight loss and exercise. Metabolism. 2012:61:1725-38.

35. Crujeiras AB, Pardo M, Arturo RR, Santiago NC, Zulet MA, Martinez JA, Casanueva FF. Longitudinal variation of circulating irisin after an energy restriction-induced weight loss and following weight regain in obese men and women. Am J Hum Biol. 2014:26:198-207.

36. de la Iglesia R, Lopez-Legarrea P, Crujeiras AB, Pardo M, Casanueva FF, Zulet MA, Martinez JA. Plasma irisin depletion under energy restriction is associated with improvements in lipid profile in metabolic syndrome patients. Clin Endocrinol. 2014;81(2):306-11.

37. Crujeiras AB, Zulet MA, Lopez-Legarrea $P$, de la Iglesia R, Pardo M, Carreira MC, Martinez JA, Casanueva FF. Association between circulating irisin levels and the promotion of insulin resistance during the weight maintenance period after a dietary weight-lowering program in obese patients. Metabolism. 2014:63:520-31.

38. Kalayci M. Preanalytical, analytical, and postanalytical errors in the measurement of irisin levels. Pol Arch Intern Med. 2017;127(9):643.

39. Albrecht E, Norheim F, Thiede B, Holen T, Ohashi T, Schering L, Lee S, Brenmoehl J, Thomas S, Drevon CA, Erickson HP, Maak S. Irisin-a myth rather than an exercise-inducible myokine. Sci Rep. 2015;9(5):8889. 
40. Jedrychowski MP, Wrann CD, Paulo JA, Gerber KK, Szpyt J, Robinson MM, Nair KS, Gygi SP, Spiegelman BM. Detection and quantitation of circulating human irisin by tandem mass spectrometry. Cell Metab. 2015;22(4):734-40.

41. Elizondo-Montemayor L, Silva-Platas C, Torres-Quintanilla A, RodriguezLopez C, Ruiz-Esparza GU, Reyes-Mendoza E, Garcia-Rivas G. Association of irisin plasma levels with anthropometric parameters in children with underweight, normal weight, overweight, and obesity. Biomed Res Int. 2017;2017:2628968

42. Hew-Butler T, Landis-Piwowar K, Byrd G, Seimer M, Seigneurie N, Byrd B, Muzik O. Plasma irisin in runners and nonrunners: no favorable metabolic associations in humans. Physiol Rep. 2015;3(1):e12262.

43. Wen MS, Wang CY, Lin SL, Hung KC. Decrease in irisin in patients with chronic kidney disease. PLoS ONE. 2013;8(5):e64025.

44. Lee DC, Pate RR, Lavie CJ, Sui X, Church TS, Blair SN. Leisure-time running reduces all-cause and cardiovascular mortality risk. J Am Coll Cardiol. 2014;64(5):472-81.

45. Choi YK, Kim MK, Bae KH, Seo HA, Jeong JY, Lee WK, Kim JG, Lee IK, Park KG. Serum irisin levels in new-onset type 2 diabetes. Diabetes Res Clin Pract. 2013;100:96-101.

46. Liu JJ, Wong MD, Toy WC, Tan CS, Liu S, Ng XW, Tavintharan S, Sum CF, Lim SC. Lower circulating irisin is associated with type 2 diabetes mellitus. J Diabetes Complicat. 2013;27:365-9.

47. Hwang Y-C, Jeon WS, Park C-Y, Youn B-S. The ratio of skeletal muscle mass to visceral fat area is a main determinant linking circulating irisin to metabolic phenotype. Cardiovasc Diabetol. 2016;15:9.

48. Chang CL, Huang SY, Soong YK, Cheng PJ, Wang CJ, Liang IT. Circulating irisin and glucose-dependent insulinotropic peptide are associated with the development of polycystic ovary syndrome. J Clin Endocrinol Metab. 2014;99:E2539-48.

49. Lee HJ, Lee JO, Kim N, Kim JK, Kim HI, Lee YW, Kim SJ, Choi Jl, Oh Y, Kim JH, et al. Irisin, a novel myokine, regulates glucose uptake in skeletal muscle cells via AMPK. Mol Endocrinol. 2015;29:873-81.

50. Meigs JB, Hu FB, Rifai N, Manson JE. Biomarkers of endothelial dysfunction and risk of type 2 diabetes mellitus. JAMA. 2004;291:1978-86.

51. Abu-Amero KK, Al-Mohanna F, Al-Boudari OM, Mohamed GH, Dzimiri $\mathrm{N}$. The interactive role of type 2 diabetes mellitus and E-selectin S128R mutation on susceptibility to coronary heart disease. BMC Med Genet. 2007;8:35.
52. Avogaro A, Albiero M, Menegazzo L, de Kreutzenberg S, Fadini GP. Endothelial dysfunction in diabetes: the role of reparatory mechanisms. Diabetes Care. 2011;34(Suppl 2):S285-90.

53. Tian J, Wen Y, Yan L, Cheng H, Yang H, Wang J, Kozman H, Villarreal D, Liu K. Vascular endothelial dysfunction in patients with newly diagnosed type 2 diabetes and effects of 2-year and 5-year multifactorial intervention. Echocardiography. 2011;28:1133-40.

54. Hamilton SJ, Watts GF. Endothelial dysfunction in diabetes: pathogenesis, significance, and treatment. Rev Diabet Stud. 2013;10:133-56.

55. Leeuwenberg JF, Smeets EF, Neefjes JJ, Shaffer MA, Cinek T, Jeunhomme TM, Ahern TJ, Buurman WA. E-selectin and intercellular adhesion molecule-1 are released by activated human endothelial cells in vitro. Immunology. 1992;77:543-9.

56. Chang TT, Chen JW. Emerging role of chemokine CC motif ligand 4 related mechanisms in diabetes mellitus and cardiovascular disease: friends or foes? Cardiovasc Diabetol. 2016;15(1):117.

57. Odegaard AO, Jacobs DR Jr, Sanchez OA, Goff DC Jr, Reiner AP, Gross MD. oxidative stress, inflammation, endothelial dysfunction and incidence of type 2 diabetes. Cardiovasc Diabetol. 2016;15:51

58. Tabak O, Simsek G, Erdenen F, Sozer V, Hasoglu T, Gelisgen R, Altunoglu E, Muderrisoglu C, Senyigit A, Uzun H. The relationship between circulating irisin, retinol binding protein-4, adiponectin and inflammatory mediators in patients with metabolic syndrome. Diabetologia. 2017;60(7):1252-60.

59. Kulidjian AA, Issekutz AC, Issekutz TB. Differential role of E-selectin and P-selectin in T lymphocyte migration to cutaneous inflammatory reactions induced by cytokines. Int Immunol. 2002;14:751-60.

60. Teixeira-Lemos E, Nunes S, Teixeira F, Reis F. Regular physical exercise training assists in preventing type 2 diabetes development: focus on its antioxidant and anti-inflammatory properties. Cardiovasc Diabetol. 2011;10:12

61. Boström P, Wu J, Jedrychowski MP, Korde A, Ye L, Lo JC, Rasbach KA, Boström EA, Choi JH, Long JZ, et al. A PGC1a-dependent myokine that drives browning of white fat and thermogenesis. Nature. 2012;481:463-8.

\section{Submit your next manuscript to BioMed Central and we will help you at every step:}

- We accept pre-submission inquiries

- Our selector tool helps you to find the most relevant journal

- We provide round the clock customer support

- Convenient online submission

- Thorough peer review

- Inclusion in PubMed and all major indexing services

- Maximum visibility for your research

Submit your manuscript at www.biomedcentral.com/submit
() Biomed Central 